\title{
Gene Expression Profile of Mesenchymal Stem Cells from Paired Umbilical Cord Units: Cord is Different from Blood
}

\author{
Mariane Secco $•$ Yuri B. Moreira $\cdot$ Eder Zucconi $\cdot$ Natassia M. Vieira $\cdot$ \\ Tatiana Jazedje • Alysson R. Muotri • Oswaldo K. Okamoto • \\ Sergio Verjovski-Almeida • Mayana Zatz
}

Published online: 7 November 2009

(C) The Author(s) 2009. This article is published with open access at Springerlink.com

\begin{abstract}
Mesenchymal stem cells (MSC) are multipotent cells which can be obtained from several adult and fetal tissues including human umbilical cord units. We have recently shown that umbilical cord tissue (UC) is richer in MSC than umbilical cord blood (UCB) but their origin and characteristics in blood as compared to the cord remains unknown. Here we compared, for the first time, the exonic protein-coding and intronic noncoding RNA (ncRNA) expression profiles of MSC from match-paired UC and UCB samples, harvested from the same donors, processed simultaneously and under the same culture conditions. The patterns of intronic ncRNA expression in MSC from UC
\end{abstract}

Mariane Secco and Yuri B. Moreira contributed equally to this work.

Electronic supplementary material The online version of this article (doi:10.1007/s12015-009-9098-5) contains supplementary material, which is available to authorized users.

M. Secco $\cdot$ E. Zucconi $\cdot$ N. M. Vieira $\cdot$ T. Jazedje $\cdot$ M. Zatz $(\bowtie)$ Human Genome Research Center, Department of Genetic and Evolutive Biology, University of São Paulo,

Rua do Matão, 106 - Cidade Universitária,

05508-090 São Paulo, SP, Brazil

e-mail: mayazatz@usp.br

Y. B. Moreira $\cdot$ S. Verjovski-Almeida

Departamento de Bioquimica, Instituto de Quimica,

Universidade de São Paulo,

05508-900 São Paulo, SP, Brazil

A. R. Muotri

UCSD Stem Cell Initiative, Department of Pediatrics and Cellular

\& Molecular Biology, University of California San Diego,

La Jolla, CA 92093-0695, USA

O. K. Okamoto

Department of Neurology and Neurosurgery,

Federal University of São Paulo,

04023-900 São Paulo, SP, Brazil and UCB paired units were highly similar, indicative of their common donor origin. The respective exonic protein-coding transcript expression profiles, however, were significantly different. Hierarchical clustering based on protein-coding expression similarities grouped MSC according to their tissue location rather than original donor. Genes related to systems development, osteogenesis and immune system were expressed at higher levels in UCB, whereas genes related to cell adhesion, morphogenesis, secretion, angiogenesis and neurogenesis were more expressed in UC cells. These molecular differences verified in tissue-specific MSC gene expression may reflect functional activities influenced by distinct niches and should be considered when developing clinical protocols involving MSC from different sources. In addition, these findings reinforce our previous suggestion on the importance of banking the whole umbilical cord unit for research or future therapeutic use.

Keywords Human umbilical cord · Human umbilical cord blood $\cdot$ Mesenchymal stem cells $\cdot$ Comparative gene expression profile

$\begin{array}{ll}\text { Abbreviations } \\ \text { MSC } & \text { Mesenchymal stem cells } \\ \text { HSC } & \text { Hematopoietic stem cells } \\ \text { UC } & \text { Umbilical cord } \\ \text { UCB } & \text { Umbilical cord blood } \\ \text { BM } & \text { Bone marrow }\end{array}$

\section{Introduction}

Multipotent mesenchymal stem cells (MSC) are an immature cell type with ability to self-renew and differentiate 
into specific functional cell types including chondrocytes, osteocytes, adipocytes, myocytes, and neurons. Phenotypic and genetic lines of evidence suggest that MSC are a useful model for developmental biology studies in normal and disease backgrounds, in addition to their therapeutic potential [1-4].

MSC were originally isolated from bone marrow (BM). Subsequently, similar populations have been reported in other tissues, such as adipose tissue [5, 6], dental pulp [7], placenta, umbilical cord blood (UCB) and umbilical cord tissue (UC), as well as from a variety of fetal tissues, such as spleen, lung, pancreas, kidney, and amniotic fluid during midgestation [8-13]. According to some authors, MSC are located in the vascular wall, constituting a MSC compartment extending throughout the entire organism [14-18]. In fact, it is known that many tissues contain lineage-committed progenitor cells for their maintenance and repair and several studies have demonstrated the presence of uncommitted MSC within the perivascular niche of several organs in animal models, where their function is to stabilize blood vessels, and to contribute to tissue homeostasis [19-21]. On the other hand, MSC seem to be absent from the circulating blood under normal physiological conditions [17, 22] and their presence in term UCB is controversial; some researchers successfully isolated MSC from UCB [10, 23-25], whereas others failed or obtained cells at low yield [11, 22, $26,27]$. We have recently shown that UC is much richer in MSC than UCB [11]. However, the question of whether the cells obtainable from both compartments were actually the same entity or not remained unanswered.

Several studies based on protein-coding gene expression profiling have been conducted with the aim of enhancing our understanding on MSC biology and ontogeny [28-33]. Further, recent investigation has demonstrated that noncoding RNAs, in addition to protein-coding genes, encompass several functions related to stem cell biology, including the maintenance of pluripotency and induction of cellular differentiation programs [34]. Given their presence in other cell-types and tissue, the noncoding transcripts are likely to be involved in other aspects of mammalian developmental and cellular biology [34-38]. More specifically, there are already a few examples of cellular mechanisms involving noncoding RNAs such as: an antisense noncoding RNA regulating usage of alternatively spliced isoforms of the Fas protein-coding gene transcribed from the same locus [39]; an antisense noncoding RNA regulating translation of the host PU.1 protein-coding gene [40]; and an intronic noncoding RNA from the CFTR locus regulating the expression of genes for specific cellular processes related to the function of the CFTR protein-coding gene [41].

Considering that large-scale expression studies are commonly restricted to protein-coding genes [28-33], studying the new and expanding class of noncoding RNA transcripts in a genome-wide scale is of great interest and may enhance our understanding of their biological functions in MSC.

Here, we analyzed, for the first time, the exonic proteincoding and intronic noncoding RNA expression profiles from match-paired UCB and UC samples, which were harvested from the same donors, processed simultaneously, and kept under the same culture conditions. The intronic noncoding RNA expression pattern of MSC from UC and UCB paired samples were highly similar suggesting that they share a common cellular origin. Surprisingly, we found significant differences in the global exonic protein-coding transcript expression patterns of MSC from UCB and UC paired samples, suggesting tissue specificity. These findings provide new insights on the biology and ontogeny of MSC in vivo, and add new information to be considered when developing clinical protocols involving MSC obtained from different sources.

\section{Materials and Methods}

\section{Harvesting of UC and UCB}

Sixty-five human UC and UCB matching units were collected after informed consent from all mothers and in accordance with the ethical committee of Jesus, José e Maria Hospital, University Hospital and Institute of Bioscience of University of São Paulo.

UCB was harvested from each sample, and conserved with $100 \mathrm{mM}$ EDTA anticoagulant at $22^{\circ} \mathrm{C}$. Sections of $8-10 \mathrm{~cm}$ of umbilical cords, which are routinely discarded, were internally washed with phosphate-buffered saline (PBS), supplemented with 3\% penicillin/streptomycin (Invitrogen-Gibco, Grand Island, NY, http://www.invitrogen.com) and immediately immersed in Dulbecco's modified Eagle's medium-low glucose (DMEM-LG; Invitrogen-Gibco) supplemented with $10 \%$ fetal bovine serum (FBS; Invitrogen-Gibco) and 3\% penicillin/streptomycin (Invitrogen-Gibco). All samples were processed within $12-15 \mathrm{~h}$ after collection.

Isolation and Culture of Adherent Cells from UCB and UC

After blood dilution of 3:1 with RPMI 1640 medium (Invitrogen-Gibco), mononuclear cells (MNCs) were isolated by density gradient centrifugation at $400 \mathrm{x} \mathrm{g}$ for $30 \mathrm{~min}$ at room temperature $\left(25^{\circ} \mathrm{C}\right)$ using Ficoll-Paque Premium (GE Healthcare, Little Chalfont, U.K., http://www.gehealthcare. com). MNCs were washed twice with PBS and resuspended in proliferation medium consisting of DMEM-LG, $10 \%$ FBS, $100 \mathrm{U} / \mathrm{ml}$ penicillin and $1 \%$ penicillin/streptomycin. Cells were plated at a density of $5 \times 10^{7}$ cells per $\mathrm{ml}$ in 
culture flasks $\left(25 \mathrm{~cm}^{2}\right)$ and maintained at $37^{\circ} \mathrm{C}$ in a humidified atmosphere containing $5 \% \mathrm{CO}_{2}$.

UCs were filled with $0.1 \%$ collagenase (Sigma-Aldrich, St. Louis, http://www.sigmaaldrich.com/sigma-aldrich/ home.html) in PBS and incubated at $37^{\circ} \mathrm{C}$ for $20 \mathrm{~min}$. Each UC was washed with proliferation medium, and the detached cells were harvested after gentle massage of the UC. Cells were centrifuged at $300 \mathrm{~g}$ for $10 \mathrm{~min}$, resuspended in proliferation medium, and seeded in $25-\mathrm{cm}^{2}$ flasks at a density of $5 \times 10^{7}$ cells per $\mathrm{ml}$.

After $24 \mathrm{~h}$ of incubation, non-adherent cells were removed, and culture medium was replaced every 3 days.

\section{Immunophenotyping}

To analyze cell-surface expression of typical protein markers, adherent cells were incubated with the following anti-human primary antibodies: CD29-PECy5, CD34-PerCP, CD31phycoerythrin (PE), CD45-fluorescein isothiocyanate (FITC), CD90-R-PE, CD73-PE, CD13-PE, CD44-PE, CD117-PE, human leukocyte antigen (HLA)-ABC-FITC, HLA-DR-R-PE (Becton, Dickinson and Company, Franklin Lakes, NJ, http:// www.bd.com). A total of 10,000 labeled cells were analyzed using a Guava EasyCyte flow cytometer running Guava ExpressPlus software (Guava Technologies Hayward, CA, http://www.guavatechnologies.com).

\section{Cell Differentiation Procedures}

To evaluate MSC properties, adherent cells (third passage, at $80-90 \%$ confluence) were subjected to adipogenic, chondrogenic, and osteogenic differentiation in vitro, according to established protocols $[4,11]$.

\section{RNA Preparation}

At $90 \%$ confluence, the MSC from four UC tissues and UCB paired samples $(n=4)$, at the second passage, were briefly rinsed with ice-cold PBS and lysed in TRIZOL reagent (Invitrogen, Carlsbad, CA, http://www.invitrogen. com) for RNA extraction. RNA purification and treatment with DNase I was performed in the 'on-column DNase digestion', according to protocol of the Qiagen RNeasy kit (Qiagen, Valencia, CA, USA). All RNA samples were checked for purity using a ND-1000 spectrophotometer (NanoDrop Technologies, Wilmington, DE, USA) and for integrity by electrophoresis on a 2100 BioAnalyzer (Agilent Technologies, Santa Clara, CA, USA).

Sample Labeling and Microarray Hybridization Procedures

Cy5- and Cy3-labeled cRNAs were obtained using $300 \mathrm{ng}$ total RNA as template for amplification of poly(A) RNA by
T7-RNA polymerase with the Agilent Low RNA Input Fluorescent Linear Amplification kit. The T7-polymerase amplified cRNA labeling approach advantageously replaces the reverse-transcriptase cDNA labeling used in early microarray experiments, because T7-RNA polymerase labeling of cRNA preserves the strand orientation of the original mRNA template. Reverse-transcriptase labeling can eventually generate a complementary cDNA second strand and cause artifactual labeling of a target with the opposite sense to that of the original message.

Hybridization of $825 \mathrm{ng}$ of Cy3- or Cy5-labeled RNA (dye swap technical replicate) from each UC sample with its paired UCB sample was performed with Agilent in situ Hybridization kit-plus, as recommended by the manufacturer, using a total of 4 intron-exon $44 \mathrm{~K}$ expression oligoarrays. This array comprises a total of 13,699 exonic probes representing different protein-coding genes, along with custom-designed intronic probes for the antisense or sense strand, as illustrated in Supplemental Figure 1 [37] (Figure S1).

Slides were washed and processed according to the Agilent Two-Color Microarray-Based Gene Expression Analysis protocol (Version 5.5) and scanned on a GenePix 4000B scanner (Molecular Devices, Sunnyvale, CA, USA). Fluorescence intensities were extracted using Feature Extraction (FE) software (version 9.0; Agilent). A gene was considered expressed if its probe intensity was significantly higher than the local background intensity, as calculated by the FE software. Then, the software applies local background subtraction and corrects for unequal dye incorporation using the default LOWESS (locally weighted linear regression) method. We have included into further statistical analyses only those genes that were detected as expressed in at least all UC samples or all CB samples as described below.

Microarray data has been deposited at the GEO database. The platform Access number is GPL9193 and the experimental series Access number is GSE18134.

\section{Statistical Analyses of Expression}

In order to identify differentially expressed transcripts between UC and UCB samples, we employed the Statistical Analysis of Microarray (SAM) approach [42] (http://wwwstat.stanford.edu/tibs/SAM/), using the following parameters: one-class analysis, 256 permutations, automatic K-Nearest Neighbors Imputer and a significance cutoff at 5\% False Discovery Rate. We performed a detailed functional annotation and description of the top 30 genes that were most significantly over-expressed in MSC from UC or UCB. To generate this list we started with the differentially expressed genes determined by the SAM analysis, ranked them by significance ( $q$-value) and subsequently by fold change, and 
we further eliminated the eventual duplicate probes for the same locus; the resulting two lists contain the 30 unique protein-coding genes over-expressed in MSC from either UC or UCB.

The set of differentially expressed protein-coding genes was further annotated by Gene Ontology (GO) terms and over-representation in functional categories was analyzed by hypergeometric distribution with the BenjaminiHochberg correction for multiple testing $(p \leq 0.05)$ using the eGOn tool [43]. Canonical pathways enrichment analyses of differentially expressed genes were performed using the Ingenuity Pathway Analysis (IPA) software (Ingenuity Systems, Redwood City, CA). This software uses a numerical value to rank the canonical pathways according to how relevant they are to the genes in the input dataset. The value is calculated taking into account the number of focus genes in the pathway and the size of the pathway in order to approximate how relevant this pathway is to the original list of focus genes. The significance value $(p \leq 0.05)$ is computed using the right-tailed Fisher's Exact Test and the $p$-value is corrected for multiple testing with the Benjamini-Hochberg method. The canonical pathway identified as significantly enriched $(p<0.05)$ is then presented as a graph indicating the molecular relationships between genes/gene products.

Using the SAM approach with the same parameters mentioned above, we found a very small number of intronic noncoding genes with statistically significant differential expression between UC and UCB samples (see Results). Therefore, in this case we chose to look for overrepresentation of GO functional categories and of enriched functions among the top 33\% most highly expressed intronic noncoding RNAs in each sample. For this purpose, each intronic noncoding transcript was functionally annotated according to the protein-coding gene of the same genomic locus and further classified by Gene Ontology terms.

\section{Real-Time Quantitative Polymerase Chain Reaction} Analysis

Differential expressions observed by microarray analysis were verified by Real-time Quantitative Polymerase Chain Reaction Analysis (RT-Q-PCR) for 7 differentially regulated genes and 1 housekeeping gene. Total RNA samples were reverse transcribed into cDNA using Superscript III reverse transcription kit (Invitrogen) and quantitative realtime PCR was performed using $1 \mu \mathrm{g}$ of cDNA and SYBR Green PCR master mix in an ABI Prism 7500 system (Applied Biosystems). Authenticity of the PCR products was verified by melt-curve analysis and agarose gel electrophoresis. Amplification efficiency of PCR products was determined by calculating the slope after semi- logarithmic plotting of the values against cycle number. Samples were run in triplicates, and the threshold suggested by the instrument software was used to calculate $\mathrm{Ct}$. Differential expression was calculated in relation to GAPDH. Data were analyzed statistically by MannWhitney test at a 0.05 level of significance. Primer sequences are provided in Supplemental Table 1 (Table S1).

\section{Results}

Isolation and Characterization of MSC from UC and UCB

MSC could be isolated from all 65 UC samples (100\%), but only from 6 out of 65 UCB samples (9\%). Previously, we had reported that the efficiency in isolating MSC from UCB stands around $10 \%$ [11].

All isolated MSC populations displayed a spindleshaped morphology (Fig. 1b, d). To evaluate MSC properties, their immunophenotype and differentiation capacity were considered. A panel of surface markers was tested by flow cytometry. MSC from all paired samples were negative for CD31 (endothelial cell marker), CD34, CD45, CD117 (hematopoietic cell markers), and HLA-DR (human leukocyte differentiation antigen class II), whereas they were positive for CD29, CD44 (adhesion markers), CD90, CD73, CD13 (mesenchymal markers), and HLAABC (human leukocyte differentiation antigen class I; Fig. 1a, c; Table 1). In vitro differentiation analysis confirmed that all isolated MSC from each matching units exhibited a comparable capacity to differentiate into osteoblasts, chondrocytes and adipocytes thus confirming their multipotent potential (Fig. 1e).

\section{Large-Scale Gene Expression Measurements in UC} and UCB Paired Samples

The observation that both populations of cells exhibit comparable properties and differentiation capacity, characteristic of MSC, does not exclude the possibility that they may differ in their potential to originate different cell lineages. To further evaluate how similar were MSC from UCB and UC paired samples, we examined their respective gene expression profiles $(n=4)$ using the $44 \mathrm{k}$ intron-exon oligoarray previously designed by our group [37].

A total of 38,960 probes are present in the oligoarray, comprising probes for exons of 13,699 protein-coding transcripts, along with 7,515 pairs of probes for totally intronic noncoding (TIN) transcripts, both for the sense (S-TIN) and anti-sense (AS-TIN) strands, plus 4,920 probes for antisense partially intronic noncoding (AS-PIN) transcripts (Table 2). The term AS-PIN is used to identify a transcript that overlaps an exon and is transcribed from the 
a

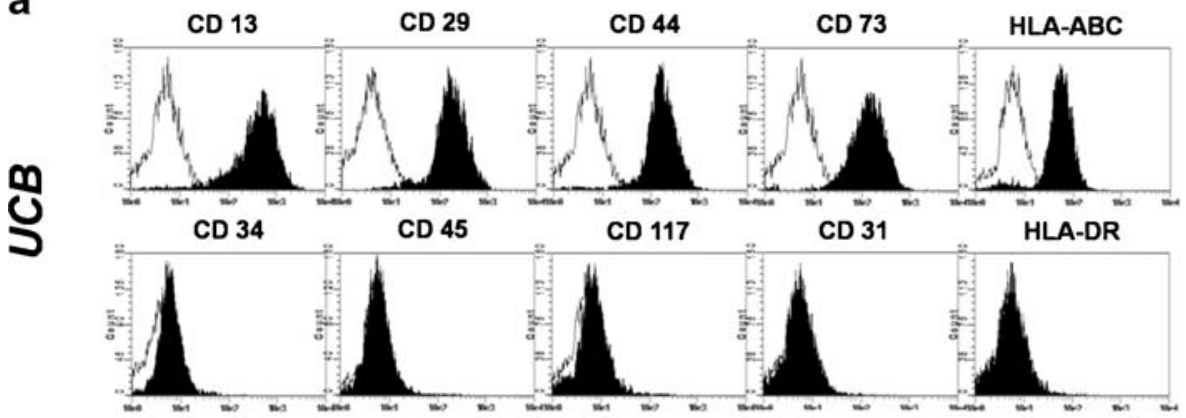

b

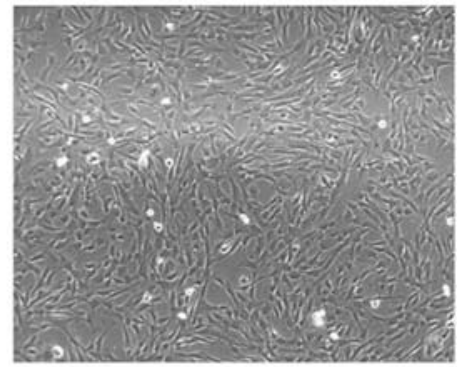

C

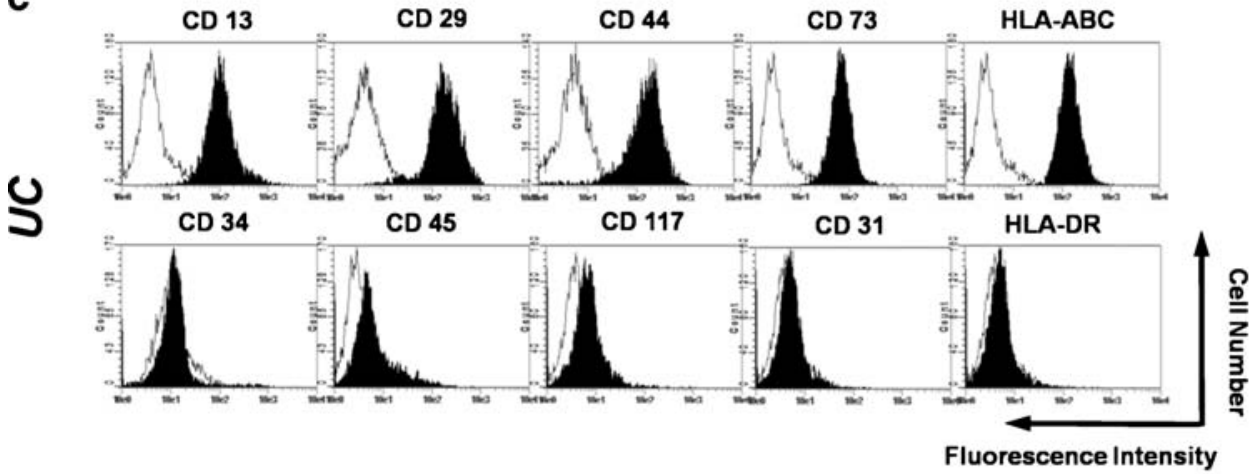

s

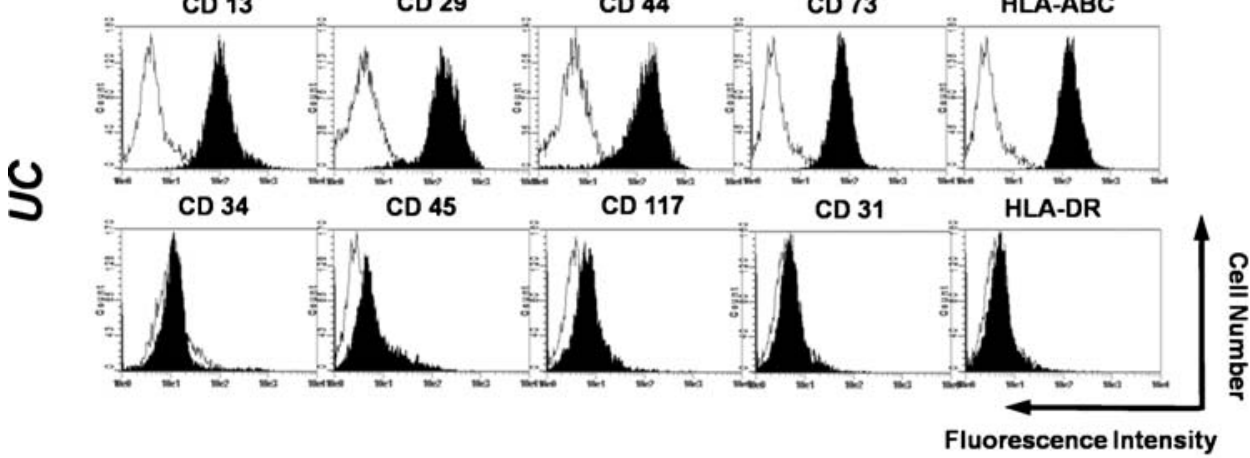

d

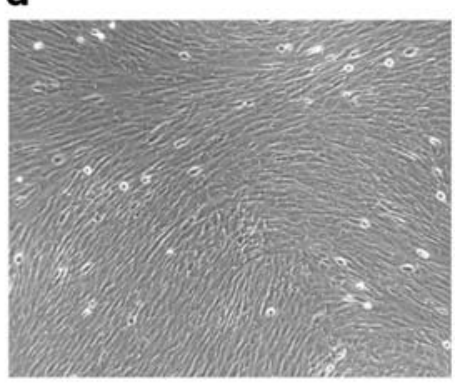

e

UNDIFFERENTIATED

ADIPOGENESIS

OSTEOGENESIS

CHONDROGENESIS
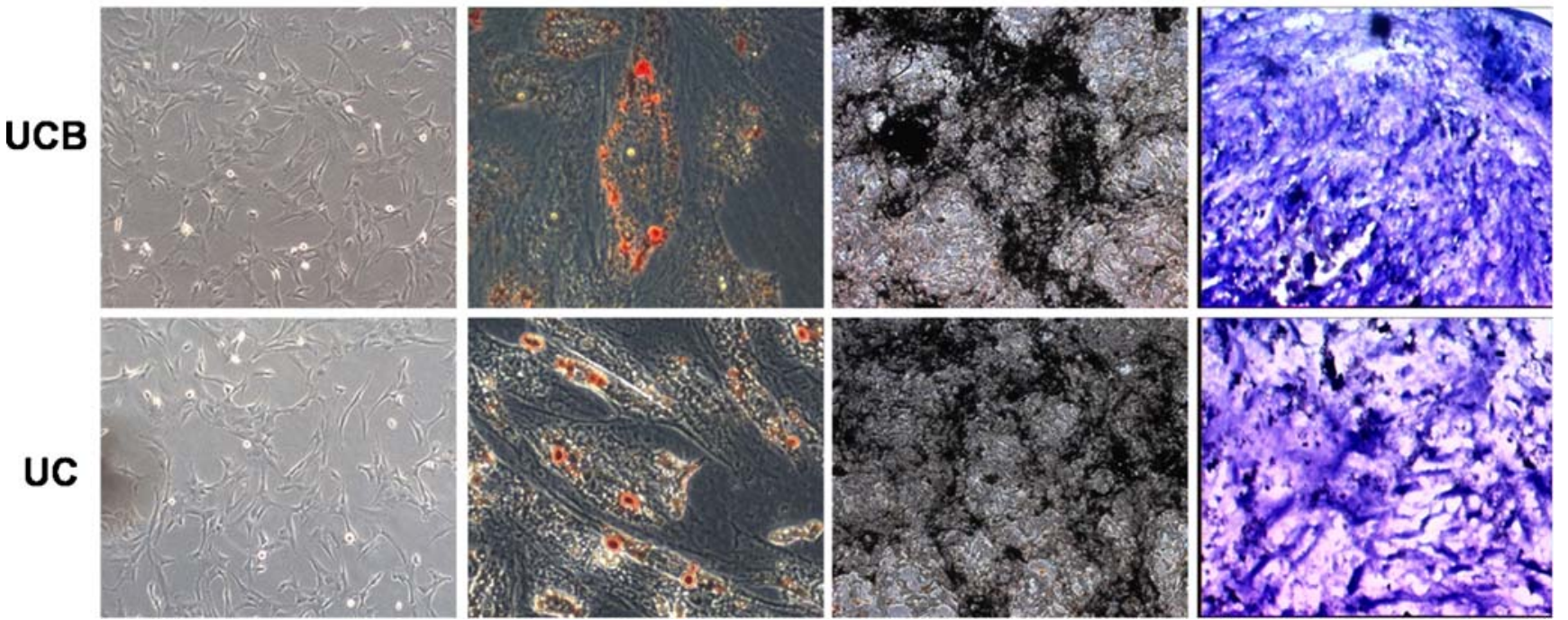

Fig. 1 Characterization of adherent cells isolated from UCB and UC. a, c Flow cytometric analysis of cell surface markers of MSC from UCB and UC, respectively. Representative histograms are demonstrated, and their respective controls are shown by the black lines. b, d Morphology of adherent cells isolated from UCB and UC. After 15 days in culture, all isolated MSC populations displayed a spindle-shaped morphology. e Differentiation potential of adherent cells isolated from UCB and UC. Osteogenic differentiation of adherent cells from UCB and UC was

opposite strand extending at least 30 bases into the adjacent introns over both ends of the exon [37] (Figure S1).

A total of 10,935 exonic, 1,645 AS-TIN, 2,651 AS-PIN and 2,420 S-TIN transcripts were found to be expressed in demonstrated by calcium deposition shown by von Kossa stain; Adipogenesis was detected by the formation of intracytoplasmic lipid droplets stained with oil red O; Cell spheres from UCB and UC were stained with toluidine blue to confirm chondrogenic differentiation. Mucopolysaccharide-rich extracellular matrix is shown in pinkish metachromatic areas. Abbreviations: $C D$ cluster of differentiation; $H L A-A B C$ human leukocyte antigen-ABC; $H L A-D R$ human leukocyte antigen-DR; $U C B$ umbilical cord blood; $U C$ umbilical cord

UCB and UC samples (Table 2) and were further analyzed for differential expression as described in the next section.

Reproducibility in the microarray experiments was assessed by dye swap technical replicate using separately 
Table 1 Summary of surface markers expression in MSC from UCB and UC

\begin{tabular}{lrr}
\hline Surface Marker & UCB $(\%)$ & UC (\%) \\
\hline Control & 0.84 & 0.98 \\
CD 13 & 98.18 & 96.64 \\
CD 29 & 97.88 & 97.94 \\
CD 44 & 97.72 & 97.18 \\
CD73 & 98.26 & 98.84 \\
CD 34 & 1.46 & 3.26 \\
CD 45 & 1.10 & 4.54 \\
CD 117 & 1.88 & 1.38 \\
CD 31 & 1.22 & 1.28 \\
HLA-ABC & 93.10 & 99.82 \\
HLA-DR & 1.68 & 1.94 \\
\hline
\end{tabular}

Data represent the mean of 3 different samples $(n=3)$. The results showed are percentage of positive cells

$H L A-A B C$ human leukocyte antigen-ABC; $H L A-D R$ human leukocyte antigen-DR; $U C$ umbilical cord; $U C B$ umbilical cord blood

prepared target RNA from each MSC sample. The correlation coefficient between two microarray datasets obtained from repeated experiments was greater than 0.98 , indicating that not only each microarray system per se, but also the overall experimental procedures were highly reproducible (Figure S2).

\section{Protein-Coding Expressed Transcripts}

The entire set of expressed protein-coding genes was used for a non-supervised hierarchical clustering analysis. The dendrogram in Fig. 2a evidences that MSC isolated from the same tissue (UC or UCB) clustered together, while MSC from different tissues of the same donor were found in different clusters.
These results indicated that gene expression profiles of MSC from the same tissue were more similar than those of MSC obtained from different tissues (UC versus UCB) of the same donor, suggesting the existence of a core gene expression profile for the MSC from each tissue, independent of the inter-donor differences.

In order to determine the statistical significance of such patterns, correlation coefficients were calculated for all possible combinations of expression measurements and a Student $t$-test was applied, as described below. Considering the exonic probes for protein-coding genes, the correlation coefficient among UC samples was in the range 0.899 to 0.972 (Table 3A, Figure S3 A). A similar trend was observed in the UCB group, where the correlation coefficient was in the range 0.901 to 0.955 (Figure S3 D). In contrast, the correlation coefficient between paired UC versus UCB MSC samples from the same individuals (for example, $\mathrm{UC1}$ versus UCB1) was in the range 0.837 to 0.925 (Figure S3 B, C).

The correlation coefficient for comparisons within UC samples (Table 3A) was significantly higher than the correlation for comparisons between UC versus UCB within the same individual $(p=0.026)$ (Table 3A). A similar trend was observed for the UCB samples, although this difference was not statistically significant $(p=0.067)$ (Table $3 \mathrm{~A})$.

\section{Differential Gene Expression of Protein-Coding Genes in UC and UCB Tissues}

To identify the individual gene expression signature of each group of MSC, we used a one-class paired analysis with the SAM statistical approach (Fig. 3).

A total of 1,054 different protein-coding genes were expressed at significantly higher levels in MSC from UC while 816 genes were significantly higher in MSC from UCB (Table 2). The full list of differentially expressed genes is shown in Supplemental Table 2 (Table S2).

Table 2 Protein-coding and noncoding genes expressed in MSC from UC and UCB tissues

\begin{tabular}{|c|c|c|c|c|c|c|c|c|c|c|c|c|}
\hline & \multicolumn{2}{|l|}{ Exonic } & \multicolumn{8}{|c|}{ Intronic } & \multicolumn{2}{|c|}{ All ncRNAs } \\
\hline & \multirow[t]{2}{*}{ probes } & \multirow[t]{2}{*}{$\%$} & \multicolumn{2}{|c|}{ AS-TIN } & \multicolumn{2}{|l|}{ S-TIN } & \multicolumn{2}{|c|}{ AS-PIN } & \multicolumn{2}{|c|}{ Other ncRNA } & \multirow[b]{2}{*}{ probes } & \multirow[b]{2}{*}{$\%$} \\
\hline & & & probes & $\%$ & probes & $\%$ & probes & $\%$ & probes & $\%$ & & \\
\hline On the Array & 13699 & 100 & 7515 & 100 & 7515 & 100 & 4920 & 100 & 662 & 100 & 20612 & 100 \\
\hline \multirow[t]{2}{*}{ Expressed in UC and UCB } & 10935 & 80 & 1645 & 22 & 2420 & 32 & 2651 & 54 & 454 & 69 & 7170 & 35 \\
\hline & probes & $\%^{\mathrm{a}}$ & probes & $\%^{\mathrm{a}}$ & probes & $\%^{\mathrm{a}}$ & probes & $\%^{\mathrm{a}}$ & probes & $\%{ }^{\mathrm{a}}$ & probes & $\%{ }^{\mathrm{a}}$ \\
\hline Over-expressed in UC (FDR 5\%) & 1054 & 10 & 30 & 2 & 68 & 3 & 118 & 5 & 18 & 4 & 234 & 3 \\
\hline Over-expressed in UCB (FDR 5\%) & 816 & 8 & 25 & 2 & 124 & 5 & 51 & 2 & 19 & 4 & 219 & 3 \\
\hline Total differentially expressed & 1870 & 18 & 55 & 4 & 192 & 8 & 169 & 7 & 37 & 8 & 453 & 6 \\
\hline
\end{tabular}

$U C B$ umbilical cord blood; $U C$ umbilical cord

${ }^{\text {a }}$ Percent over-expressed probes is calculated in relation to the total number of probes of this category that are expressed in UC and UCB 

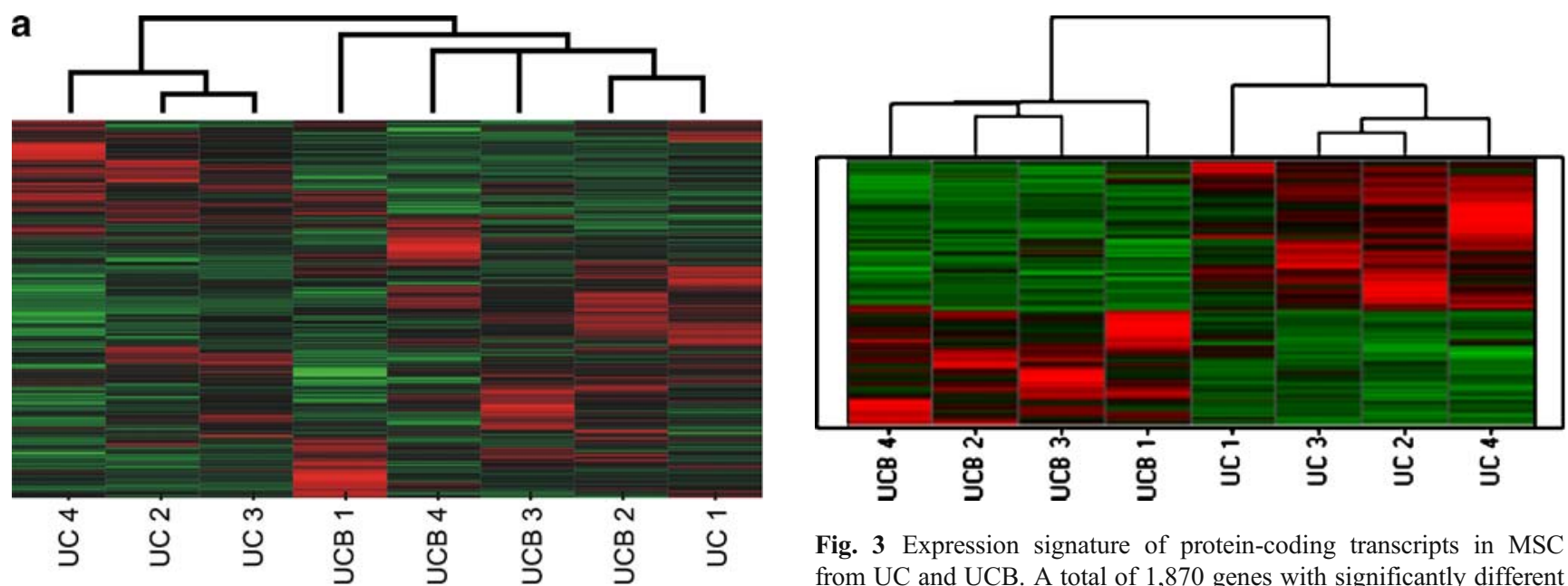

Fig. 3 Expression signature of protein-coding transcripts in MSC from UC and UCB. A total of 1,870 genes with significantly different levels among MSC from UC and UCB samples were identified by SAM one-class statistical analysis (FDR $<5 \%$ ) and hierarchically clustered as described in Materials and Methods. Each row represents the relative levels of expression for a single gene, calculated as the number of standard deviations above (red) or below (green) the average expression level of that gene across the samples. Each column represents the average expression of two technical replicate $(\mathrm{Cy} 3$ and Cy5) measurements of each sample

\section{Functional Annotation of Protein-Coding Genes Over-Expressed in MSC from UC}

Genes that were found to be over-expressed in MSC from UC were functionally annotated and analyzed with two different tools. First, enriched gene ontology (GO) terms were identified with the eGOn tool. A statistically significant over-representation of genes involved in morphogenesis, cell adhesion and secretion GO categories were identified (Table S3).

Next, the Ingenuity Pathway Analysis (IPA) software was used for identifying canonical pathways that were significantly enriched. We found that the "Synaptic Long Term Depression" pathway was significantly overrepresented (adjusted $p$-value $=0.042$ ). A total of 17 genes out of 139 genes in this pathway were found to be overexpressed in MSC from UC. A scheme of the pathway (Figure S4) and the full list of genes involved (Table S4) are shown.

Table 3 Correlation coefficients $\left(r^{2}\right)$ among expression profiles

Data shown are mean \pm SD from $r^{2}$ values within each group $\left(r^{2}\right.$ data from Figure S5)

$U C B$ umbilical cord blood; $U C$ umbilical cord

\begin{tabular}{lll}
\hline $\mathrm{r}^{2}$ within same tissue & $\mathrm{UC \text {vsUCB }}$ & $p$-value \\
& $\mathrm{r}^{2}$ within same donor \\
\hline
\end{tabular}

A) Protein-coding gene expression: analysis of correlations between MSC from UC and UCB
UC
$0.94 \pm 0.025$
$0.89 \pm 0.041$
0.026
UCB
$0.92 \pm 0.019$
$0.89 \pm 0.041$
0.067

B) Noncoding gene expression: analysis of correlations between MSC from UC and UCB
$\mathrm{UC}$
$0.98 \pm 0.005$
$0.99 \pm 0.006$
0.060
UCB
$0.98 \pm 0.007$
$0.99 \pm 0.006$
0.029 
Further, we ranked genes by significance (SAM $q$-value) and chose the top 30 genes that were significantly more expressed in MSC from UC (Table 4). The over- expressed genes in MSC from UC included genes involved in neurogenesis, such as SYNPO2 (synaptoidin) and NRP2, and angiogenesis, such as FLT1 (vascular endothelial growth factor-VEGF).

Functional Annotation of Protein-Coding Genes OverExpressed in MSC from UCB

Using a method similar to the aforementioned analysis of MSC from UC, we examined the gene expression profile of
MSC from UCB. Gene ontology analysis revealed a significantly higher representation of genes involved in anatomical structure development and multicellular organism development (Table S3). Using the Ingenuity Pathway Analysis (IPA) tool we could not find any significantly over-represented canonical pathway.

Among the top 30 genes that were significantly more expressed in MSC from UCB there were genes involved in osteogenesis, such as SPP1 (secreted phosphoprotein 1, osteopontin) and POSTN (periostin, osteoblast specific factor) (Table 5), and development of B-lymphoid cells, such as EBF1 and EBF3 (early B-cell factor 1,3 ).

Table 4 Top 30 over-expressed protein-coding genes in MSC from UC

\begin{tabular}{|c|c|c|c|c|c|}
\hline \multicolumn{6}{|c|}{ Overexpressed in UC } \\
\hline Entrez Gene ID & Gene Symbol & $\begin{array}{l}\text { Mapping. } \\
\text { location }\end{array}$ & Description & $\begin{array}{l}\text { SAM q-value } \\
(\%)\end{array}$ & $\begin{array}{l}\text { Fold } \\
\text { Change }\end{array}$ \\
\hline 139065 & SLITRK4 & Xq27.3 & SLIT and NTRK-like family, member 4 & 0 & 126.1 \\
\hline 590 & $\mathrm{BCHE}$ & $3 q 26.1-q 26.2$ & butyrylcholinesterase & 0 & 88.4 \\
\hline 10580 & SORBS1 & $10 \mathrm{q} 23.3-\mathrm{q} 24.1$ & sorbin and SH3 domain containing 1 & 0 & 57.8 \\
\hline 10788 & IQGAP2 & $5 \mathrm{q} 13.3$ & IQ motif containing GTPase activating protein 2 & 0 & 53.4 \\
\hline 2321 & FLT1 & $13 \mathrm{q} 12$ & $\begin{array}{l}\text { fms-related tyrosine kinase } 1 \text { (vascular endothelial } \\
\text { growth factor/vascular permeability factor receptor) }\end{array}$ & 0 & 52.7 \\
\hline 9699 & RIMS2 & $8 \mathrm{q} 22.3$ & regulating synaptic membrane exocytosis 2 & 0 & 27.2 \\
\hline 7980 & TFPI2 & $7 \mathrm{q} 22$ & tissue factor pathway inhibitor 2 & 0 & 25.7 \\
\hline 25849 & DKFZP564O0823 & $4 q 13.3-q 21.3$ & DKFZP564O0823 protein & 0 & 25.4 \\
\hline 753 & C18orf1 & $18 \mathrm{p} 11.2$ & chromosome 18 open reading frame 1 & 0 & 23.8 \\
\hline 171024 & SYNPO2 & $4 \mathrm{q} 26$ & synaptopodin 2 & 0 & 21.1 \\
\hline 57110 & HRASLS & $3 q 29$ & HRAS-like suppressor & 0 & 19.9 \\
\hline 144100 & PLEKHA7 & $11 \mathrm{p} 15.1$ & $\begin{array}{l}\text { pleckstrin homology domain containing, family } \\
\text { A member } 7\end{array}$ & 0 & 19.0 \\
\hline 244 & ANXA8 & $10 \mathrm{q} 11.2$ & annexin A8 & 0 & 17.4 \\
\hline 1803 & DPP4 & $2 \mathrm{q} 24.3$ & $\begin{array}{l}\text { dipeptidyl-peptidase } 4(\mathrm{CD} 26 \text {, adenosine deaminase } \\
\text { complexing protein } 2)\end{array}$ & 0 & 16.8 \\
\hline 55691 & FRMD4A & 10 p13 & FERM domain containing $4 \mathrm{~A}$ & 0 & 16.1 \\
\hline 121551 & BTBD11 & $12 \mathrm{q} 23.3$ & BTB (POZ) domain containing 11 & 0 & 16.1 \\
\hline 50507 & NOX4 & $11 \mathrm{q} 14.2-\mathrm{q} 21$ & NADPH oxidase 4 & 0 & 15.1 \\
\hline 6653 & SORL1 & $11 \mathrm{q} 23.2-\mathrm{q} 24.2$ & $\begin{array}{l}\text { sortilin-related receptor, L(DLR class) A repeats- } \\
\text { containing }\end{array}$ & 0 & 14.9 \\
\hline 158038 & LRRN6C & $9 \mathrm{p} 21.2-\mathrm{p} 21.1$ & leucine rich repeat neuronal $6 \mathrm{C}$ & 0 & 14.7 \\
\hline 22998 & DKFZP686A01247 & $4 \mathrm{p} 13$ & hypothetical protein & 0 & 11.3 \\
\hline 104 & ADARB1 & $21 \mathrm{q} 22.3$ & $\begin{array}{l}\text { adenosine deaminase, RNA-specific, B1 (RED1 } \\
\text { homolog rat) }\end{array}$ & 0 & 11.2 \\
\hline 7163 & TPD52 & $8 \mathrm{q} 21$ & tumor protein D52 & 0 & 11.0 \\
\hline 23555 & TSPAN15 & $10 \mathrm{q} 21.3$ & tetraspanin 15 & 0 & 10.7 \\
\hline 55022 & FLJ20701 & $2 \mathrm{q} 36.3$ & hypothetical protein FLJ20701 & 0 & 9.4 \\
\hline 8828 & NRP2 & $2 \mathrm{q} 33.3$ & neuropilin 2 & 0 & 9.3 \\
\hline 54361 & WNT4 & $1 \mathrm{p} 36.23-\mathrm{p} 35.1$ & wingless-type MMTV integration site family, member 4 & 0 & 9.3 \\
\hline 256435 & ST6GALNAC3 & $1 \mathrm{p} 31.1$ & 1,3)-N-acetylgalactosaminide alpha-2,6-sialyltransferase 3 & 0 & 9.3 \\
\hline 5924 & RASGRF2 & $5 q 13$ & Ras protein-specific guanine nucleotide-releasing factor 2 & 0 & 9.1 \\
\hline
\end{tabular}


Table 5 Top 30 over-expressed protein-coding genes in MSC from UCB

\begin{tabular}{|c|c|c|c|c|c|}
\hline Entrez Gene ID & $\begin{array}{l}\text { Gene } \\
\text { Symbol }\end{array}$ & $\begin{array}{l}\text { Mapping. } \\
\text { location }\end{array}$ & Description & $\begin{array}{l}\text { SAM q-value } \\
(\%)\end{array}$ & $\begin{array}{l}\text { Fold } \\
\text { Change }\end{array}$ \\
\hline 84302 & C9orf125 & $9 \mathrm{q} 31.1$ & chromosome 9 open reading frame 125 & 0 & 51.5 \\
\hline 81578 & COL21A1 & $6 \mathrm{p} 12.3-\mathrm{p} 11.2$ & collagen, type XXI, alpha 1 & 0 & 40.0 \\
\hline 3679 & ITGA7 & $12 \mathrm{q} 13$ & integrin, alpha 7 & 0 & 28.1 \\
\hline 79614 & C5orf23 & $5 \mathrm{p} 13.3$ & chromosome 5 open reading frame 23 & 0 & 25.7 \\
\hline 2044 & EPHA5 & $4 q 13.1$ & EPH receptor A5 & 0 & 25.0 \\
\hline 2006 & ELN & $7 \mathrm{q} 11.23$ & elastin (supravalvular aortic stenosis, Williams-Beuren syndrome) & 0 & 23.9 \\
\hline 7373 & COL14A1 & $8 \mathrm{q} 23$ & collagen, type XIV, alpha 1 (undulin) & 0 & 23.9 \\
\hline 10631 & POSTN & $13 \mathrm{q} 13.3$ & periostin, osteoblast specific factor & 0 & 22.3 \\
\hline 5168 & ENPP2 & $8 \mathrm{q} 24.1$ & ectonucleotide pyrophosphatase/phosphodiesterase 2 (autotaxin) & 0 & 16.7 \\
\hline 5137 & PDE1C & 7p15.1-p14.3 & phosphodiesterase $1 \mathrm{C}$, calmodulin-dependent $70 \mathrm{kDa}$ & 0 & 15.3 \\
\hline 8839 & WISP2 & $20 \mathrm{q} 12-\mathrm{q} 13.1$ & WNT1 inducible signaling pathway protein 2 & 0 & 15.2 \\
\hline 183 & AGT & $1 q 42-q 43$ & angiotensinogen (serpin peptidase inhibitor, clade A, member 8) & 0 & 14.4 \\
\hline 8490 & RGS5 & $1 \mathrm{q} 23.1$ & regulator of G-protein signalling 5 & 0 & 13.9 \\
\hline 182 & JAG1 & 20p12.1-p11.23 & jagged 1 (Alagille syndrome) & 0 & 13.1 \\
\hline 1879 & EBF1 & $5 \mathrm{q} 34$ & early B-cell factor 1 & 0 & 12.5 \\
\hline 253738 & EBF3 & $10 \mathrm{q} 26.3$ & early B-cell factor 3 & 0 & 12.3 \\
\hline 2012 & EMP1 & $12 \mathrm{p} 12.3$ & epithelial membrane protein 1 & 0 & 11.7 \\
\hline 6696 & SPP1 & $4 q 21-q 25$ & $\begin{array}{l}\text { secreted phosphoprotein } 1 \text { (osteopontin, bone sialoprotein I, } \\
\text { early T-lymphocyte activation 1) }\end{array}$ & 0 & 10.9 \\
\hline 23136 & EPB41L3 & $18 \mathrm{p} 11.32$ & erythrocyte membrane protein band 4.1-like 3 & 0 & 10.7 \\
\hline 3983 & ABLIM1 & $10 \mathrm{q} 25$ & actin binding LIM protein 1 & 0 & 10.5 \\
\hline 3783 & KCNN4 & $19 \mathrm{q} 13.2$ & $\begin{array}{l}\text { potassium intermediate/small conductance calciumactivated } \\
\text { channel, subfamily } \mathrm{N} \text {, member } 4\end{array}$ & 0 & 10.2 \\
\hline 342184 & FMN1 & $15 \mathrm{q} 13.3$ & formin 1 & 0 & 10.1 \\
\hline 5328 & PLAU & $10 \mathrm{q} 24$ & plasminogen activator, urokinase & 0 & 9.2 \\
\hline 130916 & MTERFD2 & $2 \mathrm{q} 37.3$ & MTERF domain containing 2 & 0 & 8.6 \\
\hline 9510 & ADAMTS1 & $21 \mathrm{q} 21.2$ & ADAM metallopeptidase with thrombospondin type 1 motif, 1 & 0 & 8.5 \\
\hline 9783 & RIMS3 & 1pter-p22.2 & regulating synaptic membrane exocytosis 3 & 0 & 7.9 \\
\hline 57520 & HECW2 & $2 \mathrm{q} 32.3-\mathrm{q} 33.1$ & HECT, $\mathrm{C} 2$ and WW domain containing E3 ubiquitin protein ligase 2 & 0 & 7.9 \\
\hline 4629 & MYH11 & $16 \mathrm{p} 13.11$ & myosin, heavy chain 11 , smooth muscle & 0 & 7.8 \\
\hline 255488 & IBRDC2 & $6 \mathrm{p} 22.3$ & IBR domain containing 2 & 0 & 6.8 \\
\hline
\end{tabular}

Partially and Totally Intronic Noncoding Transcripts Expressed in UC and UCB Paired Samples

Table 2 shows the number of protein-coding and intronic noncoding probes expressed in all UCB and UC samples. While $80 \%$ of protein-coding messages were expressed, only $22 \%$ of antisense TIN, $54 \%$ of antisense PIN and $32 \%$ of sense TIN transcripts were expressed in the tissues. This reveals that the diversity of intronic noncoding messages was lower than that of protein-coding messages.

We looked at the overall pattern of noncoding expression using a non-supervised hierarchical clustering (Fig. 2b). One can see that the MSC isolated from different tissues of the same donor clustered together while MSC from the same tissue and different donors were found in different clusters, thus suggesting that the intraindividual intronic noncoding expression profile was less variable between MSC from UC versus UCB than among the individuals.

The correlation coefficients between the UC and UCB paired samples from the same donor were in the range 0.9790.989 (Figure S5 B, C), while the correlation coefficients among the UCB samples from different donors were in the range 0.963-0.991 (Figure S5 A), and among UC samples in the range 0.967-0.987 (Figure S5 D). Table 3B shows that the average correlation coefficient between $\mathrm{UC}$ versus $\mathrm{UCB}$ of the same donors was significantly higher $(p=0.029)$ than the average correlation coefficient among MSC from UCBs of different donors. A similar comparison with the average 
correlation coefficient among MSC from UCs of different donors showed the same trend, although the difference was not statistically significant $(p=0.060)$ (Table 3B). The statistical analysis of correlation coefficients showed that the intronic noncoding expression profile was almost invariable among the individuals and even less variable between MSC from UC versus UCB of the same donor.

Using the same statistical significance analyses, a total of $4 \%$ expressed antisense PIN, 7\% antisense TIN and $8 \%$ sense TIN transcripts were detected as differentially expressed between UC and UCB paired samples, while $18 \%$ protein-coding transcripts were detected as differentially expressed in these samples (Table 2). This indicates that the tissue signature of intronic noncoding expression was more similar than the protein-coding messages between the UC and UCB paired samples.

Functional Annotation of ncRNA Over-Expressed in MSC from UCB and UC

The top 33\% most highly expressed TIN transcripts in each group of MSC (Table S5) were functionally annotated using Gene Ontology terms. The only statistically significant (adjusted $p$-value $=0.048$ ) enriched GO categories in MSC from UC comprise genes involved in transcription, including regulation of transcription, regulation of transcriptionDNA dependent, regulation of RNA metabolic process and biopolymer biosynthetic process (Table S6). The same GO categories were the most enriched ones in MSC from UCB, although this over-representation was not statistically significant (adjusted $p$-value $=0.153)($ Table S6).

Next, the Ingenuity Pathway Analysis (IPA) software was used for identifying functions that were significantly enriched among the top 33\% most highly expressed TIN transcripts in MSC from UC and UCB. Functions related to Lymphoid Tissue Structure and Development, Cellular Development and Organ Development were shared between the samples from UC and UCB, while Visual System Development and Function was only enriched in UC. The entire list of identified functions and the genes involved are shown in Supplemental Tables 7 and 8 (Tables S7 and S8).

\section{Validation of Microarray Results with Real-Time} Quantitative PCR

Reproducibility of our microarray results has been shown to be fairly high [37] (Figure S2). Nevertheless, we have selected seven differentially expressed genes between UC and UCB samples and assessed their expression levels in $8 \mathrm{UC}$ and $6 \mathrm{UCB}$ units through RT-Q-PCR. Genes analyzed were significantly differentially expressed between UC and UCB samples $(p \leq 0.05$; Figure S6). The results were entirely consistent with DNA microarray data. Therefore, based on these results, we opted not to exhaustively reanalyze all genes of interest with RT-Q-PCR. In fact, recent microarray validation studies [44] have shown that the Agilent oligoarray technology, used in the present study, has been optimized to attain reproducible results.

\section{Discussion}

MSC are Isolated at Higher Yields from UC Compared with UCB

MSC have been defined by their plastic adherent growth and subsequent expansion under specific culture conditions, in addition to their in vitro differentiation potential into several cell types. Previous reports indicate that MSC can be found in perivascular niches of several organs [14-18] but they seem to be absent from the circulating blood under normal physiological conditions [17, 22]. However, their presence in UCB is controversial: some researchers successfully isolated MSC from UCB [23-25, 45], whereas others failed to isolate them or obtained a low yield [11, 22, 26, 27].

Based on a sample of 10 umbilical cord units, we had previously reported that under the same culture conditions, MSC could be obtained from all $10 \mathrm{UC}$ and, in contrast, from only one UCB [11, 12]. In the present study, these results were confirmed in a larger sampling, where MSC could be obtained from all 65 UC and from only 6 UCB. They support our previous observation on the importance of banking the whole umbilical cord unit as a source of MSC.

Genomic studies have provided another dimension for a detailed understanding of the MSC biology and ontogeny. Several authors have analyzed the gene expression profile of MSC, focusing mostly on three aspects: (i) changes induced during in vitro differentiation to specific cell lineages [46-50], (ii) direct comparison of gene expression profiles in population of MSC obtained from several sources [28-31, 45], and (iii) estimation of the absolute expression levels in MSC [30, 32, 33]. However these comparative studies were performed with different lineages of MSC obtained from various sources and processed under different conditions, which introduces many variables in the analysis of global gene expression profiles. A systematic comparison of the tissue expression signature of exonic and intronic noncoding transcripts of MSC derived from related sources and from match-paired samples analyzed under the same culture conditions had not been described previously.

Intronic Noncoding Transcripts are Abundantly Expresses in MSC from UC and UCB

We identified that $35 \%$ of all intronic noncoding transcripts on the array were expressed in MSC from UC and UCB, as 
opposed to $80 \%$ of exonic protein-coding genes on the array (Table 2). This reflects the fact that intronic noncoding RNAs have tissue and cell-type specific expression patterns, as demonstrated by our and other groups [34-38].

Interestingly, looking at the genomic loci of the most highly expressed noncoding transcripts in MSC from UC, the only statistically significant enriched GO categories were those associated with genes involved with regulation of transcription. The pattern found in MSC from umbilical cord samples is similar to that already observed for kidney, prostate and liver [37], emphasizing the importance of noncoding RNAs in providing an additional layer of regulatory functions in a number of different tissues [37, 51].

We also showed that both lineages of MSC share the high expression of a considerable number of intronic noncoding transcripts belonging to significantly enriched shared functional categories such as Lymphoid Tissue Structure and Development, Cellular Development and Organ Development (Tables S5, S6, S7 and S8), which supports a growing body of evidence in the literature indicating that the noncoding RNAs are related to the maintenance of pluripotency and the induction of alternative differentiation programs in stem cells [34]. Recently, Efroni et al. [52] demonstrated widespread transcription in protein-coding and noncoding regions in undifferentiated embryonic stem cells, whereas the lineage specification is driven by reduction of the transcribed portion of the genome. Since the MSC from UCB and UC analyzed here are undifferentiated and shared similar characteristics and differentiation potential, it seems reasonable that the most abundantly intronic expressed transcripts are, in fact, common to most of the cells in the culture instead of being expressed by a small subset of cells.

Nevertheless, the widespread expression of noncoding RNAs in undifferentiated cells and during the differentiation process support the hypothesis that these transcripts enclose several functions related to stem cells biology and therefore need to be considered to further understanding several fundamental biological processes of development, including ontogeny.

\section{Exonic Protein-Coding Expression Profile in MSC from UC Versus UCB}

Comparative correlation coefficients of exonic proteincoding expression profiles indicated that MSC from distinct UC samples are more similar to each other than to their UCB donor counterparts. In fact, MSC from different tissues (UC versus UCB) did not cluster together, even in paired MSC samples isolated from the same subject.

Previous studies comparing MSC obtained from unrelated individuals and different sources showed controversial results; Wagner et al. [53] demonstrated significant differences in the global gene expression patterns of MSC from adipose tissue, UCB and BM. Other studies have demonstrated that MSC populations obtained from different sources might exhibit significant differences in global gene expression patterns that are likely related to their differentiation capacities [3, 31, 54, 55]. On the other hand, some authors have reported that the gene expression profile of MSC of different sources were highly similar [28, 45]. However, all these results should be regarded with caution, because the expression analysis was based on cell cultures obtained from different donors, and processed by different methodologies that might explain, at least in part, the observed diversity and/or similarity. Indeed, it had been previously reported that culture conditions have a significant impact on the gene expression profile [45]. Since the isolation of MSC is primarily based on adherence to plastic and growth under specific culture conditions, it is not surprising that culture media, the number of passages and growth factors might play a significant role in the selection of cell populations. To exclude such variables, all our experiments were performed in MSC isolated from the same donor, cultivated under the same culture conditions and processed in the same culture passage.

Despite that, our initial analysis using the entire set of expressed protein-coding genes demonstrated a significant difference in the exonic protein-coding transcript expression profiles of MSC from UC and UCB paired samples. Therefore, we have focused on the differentially expressed genes between them. Among the genes that were exclusively over-expressed in UCB are osteopontin and osteoblast specific factor, which are involved in osteogenesis. In fact, many of the integrin ligands implicated in the adherence of osteoblasts to the extracellular matrix are expressed at higher levels in MSC from UCB including type XXI and XIV collagen and alpha 7 integrin [55]. Other genes more expressed in UCB are $E B F 1$ and $E B F$ 3, recognized to be transcript factors related to development of B-lymphoid cells [56]. Given that UCB could be representing the neonatal defense system against the earliest encountered pathogens, it is not surprising that the genes related to the immune system were over-expressed in MSC from UCB.

Among the genes that were exclusively or expressed at higher levels by MSC from UC is FLT1 (vascular endothelial growth factor), a growth factor recognized to be a main regulator of angiogenesis [55]. Other genes more expressed in MSC from UC include SYNPO2, NRP2, $C D H 2$ and NPY [57-60]. All these genes could be related to neurogenesis or synaptic transmission and regulation of neurotransmitter secretion. In fact, the only significantly enriched canonical pathway related to the genes over- 
expressed in MSC from UC was "Synaptic Long Term Depression", a pathway of neurophysiological processes. It has been recently shown that MSC isolated from BM also can express neuronal markers without induction [61, 62]. Alternatively, considering the anatomic position of $\mathrm{BM}$, it is possible that their stroma is innervated and contains nerve terminals, which may be responsible for the expression of neuron-related proteins [31]. In any case, it will be of great interest to verify whether the differential expression of some tissue specific genes in MSC from distinct sources turns them more prone to differentiate into distinct cell lines. For example, MSC from UC, in their undifferentiated state, could be more appropriate for treatment of neurodegenerative syndromes while MSC from UCB could be more suitable for bone repair. In accordance to these findings, recent functional studies in vivo have indicated that MSC from UC may be therapeutically useful in treating central nervous systems disorders, which could be mediated by their ability to promote angiogenesis and/or neurogenesis [63-66].

Although MSC of both origins are highly similar in the noncoding transcript expression pattern, the differences in their respective protein-coding gene expression profiles might be due to the influence of the distinct local environment in which they are located, reflecting the importance of the niche in establishing the phenotype of its residing stem cells [67]. Functional classification of differentially expressed genes according to the Gene Ontology categories has demonstrated an enrichment of genes in the categories of development in UCB while cell adhesion, morphogenesis, and secretion in UC. In order to determine the role of individual genes on cell fate and differentiation potential, additional functional studies will be necessary and are currently underway.

\section{Origin of MSC in Umbilical Cord Blood}

Based on the technique used for cord blood harvesting, we had previously suggested that MSC from UCB might be derived from the umbilical cord tissue, which has been shown to be an alternative source for MSC [11]. However, results from the present study, demonstrating significant differences in the global gene expression patterns of MSC from UC and UCB paired samples, led us to suggest that these cells are not the same. The origin of MSC in UCB, however, remains to be elucidated.

Since the first report, several works have postulated that multipotent stem cells are present in the perivascular niche of various tissues [68]. The hypothesis that both hematopoietic and MSC are travelling, via cord blood, from early fetal hematopoietic sites to the newly formed bone marrow [24] suggests that MSC from UCB might be derived from the perivascular niche from fetal hematopoietic sites. The observation that the quantity of MSC in UCB decreases substantially with gestational age supports this hypothesis: the highest concentration of progenitors was observed during transition from hepatic to bone marrow hematopoiesis and the decline occurred with the termination of this process at birth [69-72]. Furthermore, several lines of evidence indicate that the MSC from UCB, liver and bone marrow are similar to those present in adult bone marrow. Despite the fact that MSC from UC and UCB are not the same cells, they may share a common origin, such as the perivascular niche.

The comparative gene expression profile observed in the present study provides additional support to this hypothesis. For example, the cluster analysis strongly indicates that MSC from UC and UCB share a close relationship based on the intronic noncoding transcripts, and this relationship may reflect their common ontogeny and differentiation status. On the other hand, clustering based on the protein-coding gene expression profiles could indicate the activation of specific sets of genes related to the tissue from which they were isolated.

\section{Conclusion}

In conclusion, we demonstrated, for the first time, that the intronic noncoding transcript expression patterns of MSC from UCB and UC paired samples are highly similar, suggesting that they share a common ontogeny and differentiation status. We showed significant differences in the protein-coding gene expression profile patterns of MSC from UC and UCB paired samples. A set of genes related to osteogenesis and immune systems was more expressed in MSC from UCB, whereas higher expression in MSC from UC tissue was observed for genes that participate in pathways related to angiogenesis and neurogenesis. These results suggest that MSC from a specific source may be more efficient for a particular therapeutic target, which may have important clinical implications. They reinforce our previous suggestion on the importance of keeping the whole umbilical cord unit by umbilical cord blood banks for research or future therapeutic uses, in addition to providing insight into MSC biology and ontogeny.

Acknowledgements Collaboration of the following persons is gratefully acknowledged: members from the Jesus José e Maria and University Hospital, Paula Onofre, Maria Denise Fernandes Carvalho, Marcos Valadares, Agnes Nishimura, Cleber Trujillo, Constancia Urbani, Daniela Bueno, Roberto Fanganiello, Antonia M. P. Cerqueira, Dr. Maria Rita Passos-Bueno and Dr. Mariz Vainzof for helpful suggestions. This work was supported by a grant from CEPID-FAPESP (Centro de Pesquisa, Inovação e Difusão-Fundação de Amparo a Pesquisa do Estado de São Paulo), and by grants from FAPESP, CNPq (Conselho Nacional de Desenvolvimento Científico e Tecnológico) and INCT (Instituto Nacional de Ciência e Tecnologia). 
Disclosures The authors indicate no potential conflicts of interest.

Open Access This article is distributed under the terms of the Creative Commons Attribution Noncommercial License which permits any noncommercial use, distribution, and reproduction in any medium, provided the original author(s) and source are credited.

\section{References}

1. Gang, E. J., Jeong, J. A., Hong, S. H., Hwang, S. H., Kim, S. W., Yang, I. H., et al. (2004). Skeletal myogenic differentiation of mesenchymal stem cells isolated from human umbilical cord blood. Stem Cells, 22, 617-624.

2. Karahuseyinoglu, S., Cinar, O., Kilic, E., Kara, F., Akay, G. G., Demiralp, D. O., et al. (2007). Biology of stem cells in human umbilical cord stroma: in situ and in vitro surveys. Stem Cells, 25, 319-331.

3. Kern, S., Eichler, H., Stoeve, J., Kluter, H., \& Bieback, K. (2006). Comparative analysis of mesenchymal stem cells from bone marrow, umbilical cord blood, or adipose tissue. Stem Cells, 24, 1294-1301.

4. Zuk, P. A., Zhu, M., Ashjian, P., De Ugarte, D. A., Huang, J. I., Mizuno, H., et al. (2002). Human adipose tissue is a source of multipotent stem cells. Mol Biol Cell, 13, 4279-4295.

5. Vieira, N. M., Brandalise, V., Zucconi, E., Jazedje, T., Secco, M., Nunes, V. A., et al. (2008). Human multipotent adipose-derived stem cells restore dystrophin expression of Duchenne skeletalmuscle cells in vitro. Biol Cell, 100, 231-241.

6. Vieira, N. M., Bueno, C. R., Jr., Brandalise, V., Moraes, L. V., Zucconi, E., Secco, M., et al. (2008). SJL dystrophic mice express a significant amount of human muscle proteins following systemic delivery of human adipose-derived stromal cells without immunosuppression. Stem Cells, 26, 2391-2398.

7. Kerkis, I., Kerkis, A., Dozortsev, D., Stukart-Parsons, G. C., Gomes Massironi, S. M., Pereira, L. V., et al. (2006). Isolation and characterization of a population of immature dental pulp stem cells expressing OCT-4 and other embryonic stem cell markers. Cells Tissues Organs, 184, 105-116.

8. Gronthos, S., Brahim, J., Li, W., Fisher, L. W., Cherman, N., Boyde, A., et al. (2002). Stem cell properties of human dental pulp stem cells. J Dent Res, 81, 531-535.

9. Jiang, Y., Jahagirdar, B. N., Reinhardt, R. L., Schwartz, R. E., Keene, C. D., Ortiz-Gonzalez, X. R., et al. (2002). Pluripotency of mesenchymal stem cells derived from adult marrow. Nature, 418 , 41-49.

10. Lee, O. K., Kuo, T. K., Chen, W. M., Lee, K. D., Hsieh, S. L., \& Chen, T. H. (2004). Isolation of multipotent mesenchymal stem cells from umbilical cord blood. Blood, 103, 1669-1675.

11. Secco, M., Zucconi, E., Vieira, N. M., Fogaca, L. L., Cergueira, A., Carvalho, M. D., et al. (2008). Multipotent stem cells from umbilical cord: cord is richer than blood! Stem Cells, 26, 146-150.

12. Secco, M., Zucconi, E., Vieira, N. M., Fogaca, L. L., Cergueira, A., Carvalho, M. D., et al. (2008). Mesenchymal stem cells from umbilical cord: do not discard the cord! Neuromuscul Disord, 18 , 17-18.

13. Zuk, P. A., Zhu, M., Mizuno, H., Huang, J., Futrell, J. W., Katz, A. J., et al. (2001). Multilineage cells from human adipose tissue: implications for cell-based therapies. Tissue Eng, 7, 211-228.

14. Covas, D. T., Panepucci, R. A., Fontes, A. M., Jr Silva, W. A., Orellana, M. D., Freitas, M. C., et al. (2008). Multipotent mesenchymal stromal cells obtained from diverse human tissues share functional properties and gene-expression profile with CD146+ perivascular cells and fibroblasts. Exp Hematol, 36, 642-654.

15. Crisan, M., Yap, S., Casteilla, L., Chen, C.-W., Corselli, M., Park, T. S., et al. (2008). A perivascular origin for mesenchymal stem cells in multiple human organs. Cell Stem Cell, 3, 301-313.

16. da Silva Meirelles, L., Caplan, A. I., \& Nardi, N. B. (2008). In search of the in vivo identity of mesenchymal stem cells. Stem Cells, 26, 2287-2299.

17. da Silva Meirelles, L., Chagastelles, P. C., \& Nardi, N. B. (2006). Mesenchymal stem cells reside in virtually all post-natal organs and tissues. J Cell Sci, 119, 2204-2213.

18. da Silva Meirelles, L., Sand, T. T., Harman, R. J., Lennon, D. P., \& Caplan, A. I. (2008). MSC Frequency Correlates with Blood Vessel Density in Equine Adipose Tissue. Tissue Eng Part A.

19. Young, H. E., Ceballos, E. M., Smith, J. C., Mancini, M. L., Wright, R. P., Ragan, B. L., et al. (1993). Pluripotent mesenchymal stem cells reside within avian connective tissue matrices. In Vitro Cell Dev Biol Anim, 29A, 723-736.

20. Young, H. E., Mancini, M. L., Wright, R. P., Smith, J. C., Jr Black, A. C., Reagan, C. R., et al. (1995). Mesenchymal stem cells reside within the connective tissues of many organs. Dev Dyn, 202, 137-144.

21. Pate, D. W., Southerland, S., Grande, D. A., Young, H. E., \& Lucas, P. A. (1993). Isolation and differentiation of mesenchymal stem cells from rabbit muscle. Surg Forum, XLIV, 587.

22. Wexler, S. A., Donaldson, C., Denning-Kendall, P., Rice, C., Bradley, B., \& Hows, J. M. (2003). Adult bone marrow is a rich source of human mesenchymal 'stem' cells but umbilical cord and mobilized adult blood are not. Br J Haematol, 121, 368-374.

23. Bieback, K., Kern, S., Kluter, H., \& Eichler, H. (2004). Critical parameters for the isolation of mesenchymal stem cells from umbilical cord blood. Stem Cells, 22, 625-634.

24. Erices, A., Conget, P., \& Minguell, J. J. (2000). Mesenchymal progenitor cells in human umbilical cord blood. Br J Haematol, 109, 235-242.

25. Goodwin, H. S., Bicknese, A. R., Chien, S. N., Bogucki, B. D., Quinn, C. O., \& Wall, D. A. (2001). Multilineage differentiation activity by cells isolated from umbilical cord blood: expression of bone, fat, and neural markers. Biol Blood Marrow Transplant, 7, 581-588.

26. Mareschi, K., Biasin, E., Piacibello, W., Aglietta, M., Madon, E., \& Fagioli, F. (2001). Isolation of human mesenchymal stem cells: bone marrow versus umbilical cord blood. Haematologica, 86, 1099-1100.

27. Romanov, Y. A., Svintsitskaya, V. A., \& Smirnov, V. N. (2003). Searching for alternative sources of postnatal human mesenchymal stem cells: candidate MSC-like cells from umbilical cord. Stem Cells, 21, 105-110.

28. Jiang, Y., Vaessen, B., Lenvik, T., Blackstad, M., Reyes, M., \& Verfaillie, C. M. (2002). Multipotent progenitor cells can be isolated from postnatal murine bone marrow, muscle, and brain. Exp Hematol, 30, 896-904.

29. Majumdar, M. K., Thiede, M. A., Mosca, J. D., Moorman, M., \& Gerson, S. L. (1998). Phenotypic and functional comparison of cultures of marrow-derived mesenchymal stem cells (MSCs) and stromal cells. J Cell Physiol, 176, 57-66.

30. Tremain, N., Korkko, J., Ibberson, D., Kopen, G. C., DiGirolamo, C., \& Phinney, D. G. (2001). MicroSAGE analysis of 2, 353 expressed genes in a single cell-derived colony of undifferentiated human mesenchymal stem cells reveals mRNAs of multiple cell lineages. Stem Cells, 19, 408418.

31. Tsai, M. S., Hwang, S. M., Chen, K. D., Lee, Y. S., Hsu, L. W., Chang, Y. J., et al. (2007). Functional network analysis of the transcriptomes of mesenchymal stem cells derived from amniotic fluid, amniotic membrane, cord blood, and bone marrow. Stem Cells, 25, 2511-2523. 
32. Jia, L., Young, M. F., Powell, J., Yang, L., Ho, N. C., Hotchkiss, R., et al. (2002). Gene expression profile of human bone marrow stromal cells: high-throughput expressed sequence tag sequencing analysis. Genomics, 79, 7-17.

33. Wieczorek, G., Steinhoff, C., Schulz, R., Scheller, M., Vingron, M., Ropers, H. H., et al. (2003). Gene expression profile of mouse bone marrow stromal cells determined by cDNA microarray analysis. Cell Tissue Res, 311, 227-237.

34. Dinger, M. E., Amaral, P. P., Mercer, T. R., Pang, K. C., Bruce, S. J., Gardiner, B. B., et al. (2008). Long noncoding RNAs in mouse embryonic stem cell pluripotency and differentiation. Genome Res, 18, 1433-1445.

35. Brito, G. C., Fachel, A. A., Vettore, A. L., Vignal, G. M., Gimba, E. R., Campos, F. S., et al. (2008). Identification of protein-coding and intronic noncoding RNAs down-regulated in clear cell renal carcinoma. Mol Carcinog, 47, 757-767.

36. Mercer, T. R., Dinger, M. E., Sunkin, S. M., Mehler, M. F., \& Mattick, J. S. (2008). Specific expression of long noncoding RNAs in the mouse brain. Proc Natl Acad Sci U S A, 105, 716721.

37. Nakaya, H. I., Amaral, P. P., Louro, R., Lopes, A., Fachel, A. A., Moreira, Y. B., et al. (2007). Genome mapping and expression analyses of human intronic noncoding RNAs reveal tissue-specific patterns and enrichment in genes related to regulation of transcription. Genome Biol, 8, R43.

38. Birney, E., Stamatoyannopoulos, J. A., Dutta, A., Guigo, R., Gingeras, T. R., Margulies, E. H., et al. (2007). Identification and analysis of functional elements in $1 \%$ of the human genome by the ENCODE pilot project. Nature, 447, 799-816.

39. Yan, M. D., Hong, C. C., Lai, G. M., Cheng, A. L., Lin, Y. W., \& Chuang, S. E. (2005). Identification and characterization of a novel gene Saf transcribed from the opposite strand of Fas. Hum Mol Genet, 14, 1465-1474.

40. Ebralidze, A. K., Guibal, F. C., Steidl, U., Zhang, P., Lee, S., Bartholdy, B., et al. (2008). PU.1 expression is modulated by the balance of functional sense and antisense RNAs regulated by a shared cis-regulatory element. Genes Dev, 22, 2085-2092.

41. Hill, A. E., Hong, J. S., Wen, H., Teng, L., McPherson, D. T., McPherson, S. A., et al. (2006). Micro-RNA-like effects of complete intronic sequences. Front Biosci, 11, 1998-2006.

42. Tusher, V. G., Tibshirani, R., \& Chu, G. (2001). Significance analysis of microarrays applied to the ionizing radiation response. Proc Natl Acad Sci U S A, 98, 5116-5121.

43. Beisvag, V., Junge, F. K., Bergum, H., Jolsum, L., Lydersen, S., Gunther, C.-C., et al. (2006). GeneTools - application for functional annotation and statistical hypothesis testing. BMC Bioinformatics, 7, 470 .

44. Shi, L., Reid, L. H., Jones, W. D., Shippy, R., Warrington, J. A., Baker, S. C., et al. (2006). The MicroArray Quality Control (MAQC) project shows inter- and intraplatform reproducibility of gene expression measurements. Nat Biotechnol, 24, 1151-1161

45. Lee, R. H., Kim, B., Choi, I., Kim, H., Choi, H., Suh, K., et al. (2004). Characterization and expression analysis of mesenchymal stem cells from human bone marrow and adipose tissue. Cell Physiol Biochem, 14, 311-324.

46. Doi, M., Nagano, A., \& Nakamura, Y. (2002). Genome-wide screening by cDNA microarray of genes associated with matrix mineralization by human mesenchymal stem cells in vitro. Biochem Biophys Res Commun, 290, 381-390.

47. Nakamura, T., Shiojima, S., Hirai, Y., Iwama, T., Tsuruzoe, M., Hirasawa, A., et al. (2003). Temporal gene expression changes during adipogenesis in human mesenchymal stem cells. Biochem Biophys Res Commun, 303, 306-312.

48. Qi, H., Aguiar, D. J., Williams, S. M., La Pean, A., Pan, W., \& Verfaillie, C. M. (2003). Identification of genes responsible for osteoblast differentiation from human mesodermal progenitor cells. Proc Natl Acad Sci U S A, 100, 3305-3310.

49. Sekiya, I., Larson, B. L., Vuoristo, J. T., Cui, J. G., \& Prockop, D. J. (2004). Adipogenic differentiation of human adult stem cells from bone marrow stroma (MSCs). J Bone Miner Res, 19, 256-264.

50. Sekiya, I., Vuoristo, J. T., Larson, B. L., \& Prockop, D. J. (2002). In vitro cartilage formation by human adult stem cells from bone marrow stroma defines the sequence of cellular and molecular events during chondrogenesis. Proc Natl Acad Sci US A, 99, $4397-4402$

51. Louro, R., Smirnova, A. S., \& Verjovski-Almeida, S. (2009). Long intronic noncoding RNA transcription: expression noise or expression choice? Genomics, 93, 291-298.

52. Efroni, S., Duttagupta, R., Cheng, J., Dehghani, H., Hoeppner, D. J., Dash, C., et al. (2008). Global transcription in pluripotent embryonic stem cells. Cell Stem Cell, 2, 437-447.

53. Wagner, W., Wein, F., Seckinger, A., Frankhauser, M., Wirkner, U., Krause, U., et al. (2005). Comparative characteristics of mesenchymal stem cells from human bone marrow, adipose tissue, and umbilical cord blood. Exp Hematol, 33, 1402-1416.

54. Chang, Y. J., Shih, D. T., Tseng, C. P., Hsieh, T. B., Lee, D. C., \& Hwang, S. M. (2006). Disparate mesenchyme-lineage tendencies in mesenchymal stem cells from human bone marrow and umbilical cord blood. Stem Cells, 24, 679-685.

55. Panepucci, R. A., Siufi, J. L., Silva, W. A., Jr., Proto-Sequiera, R., Neder, L., Orellana, M., et al. (2004). Comparison of gene expression of umbilical cord vein and bone marrow-derived mesenchymal stem cells. Stem Cells, 22, 1263-1278.

56. Bond, H. M., Mesuraca, M., Carbone, E., Bonelli, P., Agosti, V., Amodio, N., et al. (2004). Early hematopoietic zinc finger protein (EHZF), the human homolog to mouse Evi3, is highly expressed in primitive human hematopoietic cells. Blood, 103, 2062-2070.

57. Agasse, F., Bernardino, L., Kristiansen, H., Christiansen, S. H., Ferreira, R., Silva, B., et al. (2008). Neuropeptide Y promotes neurogenesis in murine subventricular zone. Stem Cells, 26, 16361645.

58. Ara, J., Bannerman, P., Shaheen, F., \& Pleasure, D. E. (2005). Schwann cell-autonomous role of neuropilin-2. J Neurosci Res, $79,468-475$.

59. Lim, S. T., Lim, K. C., Giuliano, R. E., \& Federoff, H. J. (2008). Temporal and spatial localization of nectin-1 and 1-afadin during synaptogenesis in hippocampal neurons. J Comp Neurol, 507, $1228-1244$

60. Duband, J. L., Volberg, T., Sabanay, I., Thiery, J. P., \& Geiger, B. (1988). Spatial and temporal distribution of the adherens-junctionassociated adhesion molecule A-CAM during avian embryogenesis. Development, 103, 325-344.

61. Blondheim, N. R., Levy, Y. S., Ben-Zur, T., Burshtein, A., Cherlow, T., Kan, I., et al. (2006). Human mesenchymal stem cells express neural genes, suggesting a neural predisposition. Stem Cells Dev, 15, 141-164.

62. Tondreau, T., Lagneaux, L., Dejeneffe, M., Massy, M., Mortier, C., Delforge, A., et al. (2004). Bone marrow-derived mesenchymal stem cells already express specific neural proteins before any differentiation. Differentiation, 72, 319-326.

63. Weiss, M. L., Medicetty, S., Bledsoe, A. R., Rachakatla, R. S., Choi, M., Merchav, S., et al. (2006). Human umbilical cord matrix stem cells: preliminary characterization and effect of transplantation in a rodent model of Parkinson's disease. Stem Cells, 24, 781-792.

64. Fu, Y. S., Cheng, Y. C., Lin, M. Y., Cheng, H., Chu, P. M., Chou, S. C., et al. (2006). Conversion of human umbilical cord mesenchymal stem cells in Wharton's jelly to dopaminergic neurons in vitro: potential therapeutic application for Parkinsonism. Stem Cells, 24, 115-124.

65. Chen, M. Y., Lie, P. C., Li, Z. L., \& Wei, X. (2009). Endothelial differentiation of Wharton's jelly-derived mesenchymal stem cells 
in comparison with bone marrow-derived mesenchymal stem cells. Exp Hematol, 37, 629-640.

66. Liao, W., Xie, J., Zhong, J., Liu, Y., Du, L., Zhou, B., et al. (2009). Therapeutic effect of human umbilical cord multipotent mesenchymal stromal cells in a rat model of stroke. Transplantation, 87, 350359.

67. Fuchs, E., Tumbar, T., \& Guasch, G. (2004). Socializing with the neighbors: stem cells and their niche. Cell, 116, 769-778.

68. Abedin, M., Tintut, Y., \& Demer, L. L. (2004). Mesenchymal stem cells and the artery wall. Circ Res, 95, 671-676.

69. Campagnoli, C., Roberts, I. A., Kumar, S., Bennett, P. R., Bellantuono, I., \& Fisk, N. M. (2001). Identification of mesenchymal stem/progenitor cells in human first-trimester fetal blood, liver, and bone marrow. Blood, 98, 2396-2402.
70. Christensen, J. L., Wright, D. E., Wagers, A. J., \& Weissman, I. L. (2004). Circulation and chemotaxis of fetal hematopoietic stem cells. PLoS Biol, 2, E75.

71. Surbek, D. V., Holzgreve, W., Jansen, W., Heim, D., Garritsen, H., Nissen, C., et al. (1998). Quantitative immunophenotypic characterization, cryopreservation, and enrichment of second- and third-trimester human fetal cord blood hematopoietic stem cells (progenitor cells). Am J Obstet Gynecol, 179, 1228-1233.

72. Wyrsch, A., dalle Carbonare, V., Jansen, W., Chklovskaia, E., Nissen, C., Surbek, D., et al. (1999). Umbilical cord blood from preterm human fetuses is rich in committed and primitive hematopoietic progenitors with high proliferative and selfrenewal capacity. Exp Hematol, 27, 1338-1345. 